\title{
Corporate social responsibility and firm performance in South Africa
}

\author{
K. Demetriades and C.J. Auret* \\ School of Economics and Business Sciences, University of the Witwatersrand \\ Private Bag X3, Wits, 2050, Republic of South Africa \\ kimond@icon.co.za; christo.auret@wits.ac.za
}

\begin{abstract}
Corporate Social Responsibility (CSR) can be viewed from two different perspectives: that of the business; and that of the individual investor (Socially Responsible Investing, SRI). In this study regression analysis as well as an event study was used to examine the link between CSR and firm performance. The results suggested that in the short-term there were no significant price effects on the SRI shares. In contrast, the returns of SRI portfolios over the sample period seemed to be superior to those of conventional firms. The regression analysis found that generally the SRI coefficients were insignificant; however using one of the models during the fifteen year sample period, SRI constituents attained a ROE that was $11.18 \%$ higher (as well as a ROA that was $1.824 \%$ lower) than conventional firms. When the period was restricted to 2004-2009 it was found that social performance was positively - and sometimes significantly - correlated with ROE.
\end{abstract}

*To whom all correspondence should be addressed.

\section{Introduction}

Corporate Social Responsibility (CSR) and sustainability have become two key catchphrases in the management of business today; however the justification behind them is not always clearly understood. This paper attempts to give some background to these phenomena, as well as apply methodologies for the examination of these topics in South Africa. Milton Moskowitz (1972) was one of the first researchers to formally suggest that socially responsible firms may perform better than conventional firms. Since then there have been numerous articles in academic literature dedicated to this topic, and through this debate there have been a few critical questions raised including 'Do socially responsible firms outperform conventional firms?'; 'Do Socially Responsible Investments (SRI) perform as well as conventional investments?' and 'What is the direction of these effects?'. A major shortcoming in the research is that there is no consistent and reliable measure for Corporate Social Performance (CSP). Due to its diverse and sometimes intangible nature it is hard to measure performance in social arenas and therefore numerous methodologies have been proposed to account for this.

In South Africa, as a result of the King reports on corporate governance as well as the Johannesburg Stock Exchange (JSE) listing requirements, social responsibility and sustainability have been pushed to the forefront of the psyche of companies operating locally. These initiatives have impressed upon local firms a need for some level of sustainability (or social responsibility) and as a consequence have raised the awareness of the local businesses and investment community. SRI can be expressed using different techniques which include negative as well as positive screening. Positive screening essentially tilts portfolios towards good social performers while negative screens exclude firms with negative performance in the Environmental, Societal and Governmental (ESG) areas. As a direct consequence of these screens investors are able to incorporate ethical and ESG concerns into the investment decision making process. CSR can be seen as sustainability from the firm perspective and is the realization that externalities affecting society should be accounted for in everyday operational decisions - while SRI is the most widely accepted expression of support from the markets for good CSR practices. Thus, by accepting SRI, investors can promote and encourage growth in CSR and sustainability.

A report by the Social Investment Forum examining trends in the United States found that during 1995-2012 SRI assets grew by $486 \%$ versus the broader universe of assets which grew by $376 \%$. Around $11,3 \%$ of total assets under management tracked by Thomson Reuters Nelson were engaged in SRI which amounted to around one in nine dollars (Social Investment Forum, 2012). It is apparent that due to the increased interest in this topic as well as its relevance in today's society further research, especially in a local context, is warranted. The UN developed a set of principles for responsible investment (UNPRI) where the aim of the signatories and principles was to improve on the situation regarding social responsibility by encouraging improved disclosure and efforts in social arenas. The Government Employees Pension Fund (GEPF) became a signatory and as a result asset managers wishing to do business with the GEPF were required to become compliant (Masie, 2008). The GEPF has stated that its strategy is to integrate ESG issues into investment decisions and ownership practices - where core objectives include protecting and enhancing the long-term value of its investments. Another objective is to fulfill the responsibilities to society by encouraging investment that 
addresses socioeconomic imbalances (Government Employees Pension Fund, 2009: 7).

It has been hypothesized that the relationship between social and financial performance persists in the long term. Some literature has suggested that accounting returns may best capture the firms' unique characteristics and internal efficiencies (Orlitzky, Schmidt \& Rynes, 2003). Alternatively, market returns encompass investor perceptions about the future and in efficient markets may be sufficient to indicate a relationship between CSP and Corporate Financial Performance (CFP). For market returns, efficient markets adjust instantaneously to information that was previously unknown, unexpected and material therefore this relationship needs to be examined in the short run. Two methods of examining the CSP-CFP relationship were looked at: regressions using financial ratios were used for the long run (Waddock \& Graves, 1997; McWilliams \& Siegel, 2000; Callan \& Thomas, 2009), and an event study examining abnormal price adjustments was used in the short run (McWilliams \& Siegel, 1997). Both approaches study social responsibility from the firm perspective where this involves looking at the costs of social responsibility versus the benefits that may be present. Thus the relationships that can be determined tell us whether the benefits from social responsibility outweigh the costs or not.

From the investors' perspective, SRI involves investing according to one's ethical and ESG considerations. In this study socially responsible firms were compared to conventional firms, and the relative performances were examined. The relationships can be expressed in positive, negative or neutral directions; however, for the purpose of this paper only explicit negative findings are taken as evidence against CSR and SRI. This is because in the event of neutral findings, the costs to the firms and investors have been balanced by the benefits. However the additional externalities inherent in the benefits to society, or the utility derived from investing according to one's beliefs have been excluded from this calculation. Therefore, while from a monetary standpoint the conventional and socially responsible standpoints seem equivalent, the additional societal benefits suggest the evidence favours the idea of CSR. It has been suggested that asset pricing models should include behavioral aspects and that utilitarian as well as value-expressive characteristics should be included in decision making processes (Statman, 2000). Although the majority of literature has found no difference in performance between SRI and conventional funds, investors are able to derive additional value-expressive benefits from social participation which was previously lacking in traditional investments. This paper examines the role of CSR from the perspectives of the corporation as well as the investor in a South African setting.

\section{Literature review}

The origins of SRI can be traced far back in history from early Jewish law that laid down directives on how to invest, to the $18^{\text {th }}$ century religious institutions that brought the idea of SRI to the new world by avoiding companies involved with war and slavery. Social screens can be defined as the use of a non-financial criterion applied in the investment decision-making process (Kinder \& Domini, 1997). CSR as a corporate practice makes it easier for investors to determine which firms are worth investing in and which should be avoided if ethical investing is what they desire. New ideas such as the Triple Bottom Line have tried to formalize a measurement for social performance, however, it has been contended that it is not so easy to measure, calculate, audit and report social performance (Norman \& MacDonald, 2003). In this way it differs from the traditional bottom line, and therefore without the tools required to measure other bottom lines properly, the concept is not as useful as some believe. Ultimately the inherent emptiness and vagueness of this paradigm makes it easy for cynical firms to appear committed to social responsibility. One of the pillars of CSR and the ESG ideal is that of corporate governance - which has been gaining traction in recent years. Global corporate failures have tuned society towards the possibility of what can go wrong in mismanaged firms. Gompers, Ishii \& Metrick (2003) studied the effects of governance and found that those with better governance performed better financially. Good governance essentially protects the shareholders from any agency costs imposed by management, while the rest of CSR aims to protect the environment and society from any negative externalities generated by the corporation. These ideas become more important as the King Committee and the JSE listing requirements aim to institute improved governance systems in local companies.

Moskowitz (1972) advanced the idea of corporate social responsibility when he suggested that responsible companies outperform conventional firms. Friedman (1970) offered an alternative argument with the often paraphrased idea that a corporation's only responsibility should be to use its resources to increase profits as long as it does not break any rules. If managers spent shareholders' money on their own ideals, this was not in the interest of society and if they wanted to do 'good' they should do so at their own expense. Ultimately the business of business is business, and using the guise of CSR for otherwise profit motivated activities is tantamount to fraud. Very few academics have been in agreement with such vocal opposition to the idea, and generally the research has followed the idea that there is no statistically significant relationship between CSP and CFP. This generally ignores any positive externalities generated by these social initiatives, thus the net benefit to society might be larger, even if the firm does not see any tangible benefits. Fitch (1976) stated that corporations can achieve CSR if they attempt to identify and solve those social problems in which they are intimately involved, and when the possibility of profit is available as an incentive. This stemmed from the author's belief that corporations are perhaps the most effective problem-solving organisations in a capitalist society and it seemed likely that they would take on the additional burden of solving broader social problems. Carroll (1979) offered a framework where CSR could fit into business operations considering economic, legal, ethical 
and discretionary responsibilities as well as the demand for CSR attributes.

One of the more structured arguments for CSR came from Porter \& Kramer (2006) who suggested that CSR should be used as an opportunity for success. According to the authors companies should analyze prospects for CSR in the same way they do their core business choices. In this way CSR can be a source of innovation and competitive advantage. Ideally corporations should not focus on the tension between business and society; instead identifying the points of intersection, choosing social issues to address, creating a social agenda, and adding a social dimension to the value proposition. The most strategic CSR occurs when a company adds this social dimension, making social impact integral to the overall strategy. Corporations are not responsible for the world's problems but if companies identify the social problems they are equipped to resolve and from which they can gain competitive benefit; addressing these issues by creating shared value will lead to selfsustaining solutions.

Numerous papers looked at the relationship between CSP and CFP where the findings varied from no significant relationship (Aupperle, Carroll \& Hatfield, 1985) to mild and strong positive links (Cochran \& Wood, 1984; Waddock \& Graves, 1994; Waddock \& Graves, 1997; Orlitzky, Schmidt \& Rynes, 2003; Callan \& Thomas, 2009). Very few papers found explicitly negative links in terms of this relationship, and as discussed this can be taken as a positive for the ideal as a whole.

The relationship between CSP and CFP is important to SRI insofar as the direction of the relationship determines if socially responsive firms will do well financially or suffer from the costs of these initiatives. Grossman and Sharpe (1986) examined the effect of divestments of South African shares during apartheid and found that the divested portfolio marginally outperformed the NYSE in the sample period. Teoh, Welch \& Wassan (1999) used an event study to investigate the effects of the South Africa boycott; however, they found that there were no valuation effects on the financial sector despite the prominence and publicity of the boycott. While the sanctions may have raised moral standards and public awareness, the financial markets avoided the brunt of the sanctions. Diltz (1995) found that ethical screening of portfolios neither helps nor hinders portfolio performance, which was good news for investors concerned with ownership of good corporate citizens.

Overall the majority of literature in this section found no difference in performance between SRI investments and conventional funds (Arlow \& Gannon, 1982; Aupperle et al., 1985; Diltz, 1995; McWilliams \& Siegel, 2000), however, for the development of SRI it must be understood that SRI is not an end in itself but rather a central component of CSR. Investors can use SRI to influence businesses to achieve more sustainable development; and by improving engagement with companies on investments, business would be able to respond to the social and ethical concerns raised by conscientious investors. As mentioned already, the lack of a significant relationship between CSP and CFP does not mean there is no benefit to be derived, as investors gain additional utility from their ethical investments. Similarly, corporations with social initiatives may be as profitable as their less responsive competitors; however society is deriving additional benefit through the positive externalities inherent in these initiatives.

Out of the top 100 economic entities in the world around half are corporations while the rest are countries (Anderson \& Cavanagh, 2000). This finding demonstrates the importance that large firms play in our society and hence why the 'social responsibility' of firms may not necessarily be something external to the firm, but rather a part of their internal processes and activities. With great power and influence comes responsibility; and without restricting business too much, attention should be paid to the externalities produced by these multinational companies. Porter \& Kramer (2006) offer the example of Nestle in India where they entered the region in a bid to secure milk suppliers. By offering improved methods, technologies as well as infrastructure, they created a value chain they could depend on while simultaneously improving the lives of local farmers and improving the local economy. As a result of their prosperity the region where Nestle operated had a significantly higher standard of living when compared to other regions including access to more doctors, telephones, schools as well as electricity. Thus, the socially responsible behaviour became a part of their business strategy and by investing in the community Nestle was able to build up a competitive advantage as well as help develop the local community.

Bernstein (2010) made a case for developing nations, and while CSR was covered it was framed as anti-business as the responsibilities put on companies did more harm than good. In this way, the 'generic' approach to CSR that Porter \& Kramer (2006) highlighted does appear to hinder progress as there is no strategy behind the initiatives, and they may miss the mark in terms of social as well as business benefits. It was contended that business should be recognized for the inherent good that comes out of everyday operations, however the key may be in finding the middle ground between the business case, and the CSR case which impressed responsibilities on corporations. Bernstein (2010) stated that business needs to align its interest with social involvement and build on business strengths as opposed to working in areas far removed from company activities - an idea similar to Porter \& Kramer (2006) who suggested finding the intersections between social issues and business operations and adding a social aspect to the value proposition. As South Africa is a developing nation, it may pay to understand the inherent differences in our economy when compared to developed countries. In this way, CSR can be approached with the attention it deserves as opposed to adopting it for the sake of compliance with global standards. 


\section{Research Methodology}

The methodologies used in this paper were based on earlier empirical literature and spanned short-term as well as longterm periods. It has been noted (Waddock \& Graves, 1994; Aupperle et al., 1985) that measuring CSP consistently is usually extremely challenging. Some of the potential measures include surveys, using Fortune Magazine ratings, content analysis, behavioural measures and case studies. Most of these approaches have significant limitations and it is likely that an amalgamation of methods is the most appropriate approach. Using the JSE's SRI index as a proxy seemed acceptable in that EIRIS, the research company doing the analysis, included reputational indexes as well as content analysis in their research. Although the degree of social responsibility could not be determined using the data, it was trivial to classify between performers (SRI index participants) and non-performers (conventional firms).

This paper examined the question of CSR from two perspectives, firstly from the standpoint of the actual company involved in CSR, and secondly from the standpoint of the investor who chooses to invest in line with their beliefs. From the firm perspective it is fundamental to understand how CSR affects the bottom line as well as the firm's fundamental characteristics. In this way it can be determined if CSR is viable (the benefits are greater than the costs). For the investor the key here is whether socially responsible investments deliver comparable performance to that of conventional investments. The questions for this perspective examine whether there is a cost to social investing. It is possible that the costs and benefits offset, thus leaving the SRI investor no worse off. Alternatively if the costs are greater than the benefits the investor must 'pay' to incorporate their ethical and ESG beliefs into their investments. The final alternative is that the benefits outweigh the costs and this would mean SRI investments are appealing for any investor regardless of their CSR preference.

CSR can be examined in the short term as well as the long term. For the short term an event study was used where the methodology was taken from McWilliams \& Siegel (1997). Price changes around the time of the SRI constituent list announcements were examined to see if any information effects were contained. Some limitations as noted by Arlow \& Gannon (1982) were that market returns based on share valuation may be sensitive to other factors such as the state of the economy. The reasoning behind this approach was that if investors value the social aspect of business, the announcement may change investor perceptions about the company with a resulting share price change. The following steps outline the methodology used:

1) Define the event; 2) Outline theory justifying a financial response to event; 3) Identify firms experiencing this event; 4) Choose event window; 5) Adjust for firms experiencing other relevant events; 6) Compute abnormal returns as well as significance; 7) Report test statistics
Abnormal returns were calculated as those deviating from the returns predicted by the market model (over an estimation period from 250 to 50 days prior to the event dates):

$$
\mathrm{AR}_{\mathrm{it}}=\mathrm{R}_{\mathrm{it}}-\left(\mathrm{a}_{\mathrm{i}}+\mathrm{b}_{\mathrm{i}} \mathrm{R}_{\mathrm{mt}}\right)
$$

This was then standardised as:

$\mathrm{SAR}_{\mathrm{it}}=\mathrm{AR}_{\mathrm{it}} / \mathrm{SD}_{\mathrm{it}}$

where:

$\mathrm{SD}_{\mathrm{it}}=\left\{\mathrm{S}_{\mathrm{i}}^{2} \mathrm{x}\left[1+1 / \mathrm{T}\left(\mathrm{R}_{\mathrm{mt}}-\mathrm{R}_{\mathrm{m}}\right)^{2} / \Sigma\left(\mathrm{R}_{\mathrm{mt}}-\mathrm{R}_{\mathrm{m}}\right)^{2}\right]\right\}^{0.5}$

These returns were then cumulated:

$\mathrm{CAR}_{\mathrm{i}}=\left(1 / \mathrm{k}^{0.5}\right) \Sigma \mathrm{SAR}_{\mathrm{it}}$

and the average calculated:

$\mathrm{ACAR}_{\mathrm{t}}=1 / \mathrm{n} \times 1 /[(\mathrm{T}-2) /(\mathrm{T}-4)]^{0.5} \Sigma \mathrm{CAR}_{\mathrm{it}}$.

The test statistic was calculated as:

$\mathrm{Z}=\mathrm{ACAR}_{\mathrm{t}} \times \mathrm{n}^{0.5}$

The long term approach entailed using regression analysis to compare FTSE/JSE SRI firms to conventional firms. A caveat with the sample is that the majority of the JSE Top 40 shares were SRI constituents which are important as comparable firms of equal size could not be found. This could mean either that those firms with more resources can afford to be more responsible or alternatively good CSP may have helped the companies perform even better relative to their peers. McWilliams \& Siegel (2000) proposed a regression model using a proxy for CSP where a dummy variable represented whether a firm was in the Domini Social Index. A similar analysis was performed using a model with the JSE's SRI index as the proxy; in addition to other models from the literature (Callan \& Thomas, 2009; Waddock \& Graves, 1997).

As noted in the previous literature (McGuire et al., 1988; Waddock \& Graves, 1997) past as well as future performance is important. The analysis helps us understand the direction of causality in the CFP-CSP relationship. Regressions were run using the SRI dummy variable indicating social performers versus conventional firms. In terms of CFP, measures such as Earnings per Share, P/E, Return on Assets (ROA) and Return on Equity (ROE) were suggested. However, due to the fact that market returns are sensitive to external factors accounting measures were used as the main financial measure for the regression analyses. It has also been found that accounting measures are more closely correlated with CSP (Orlitzky et al., 2003; McGuire, Sundgren \& Schneeweis, 1988) - therefore ROA and ROE were the two main CFP measures examined. An important control variable was the firm's industry (Arlow \& Gannon, 1982; Cochran \& Wood, 1984; Waddock \& Graves, 1994, 1997 ) and a dummy representing this was included in the regression models. 
CFP $=a_{0}+a_{1}$ SRI $+a_{2}$ SIZE $+a_{3}$ RISK $+a_{4}$ ConsServ + $\mathrm{a}_{5}$ Financials $+\mathrm{a}_{6}$ BasicMat $+\mathrm{a}_{7}$ Telecomm $+\mathrm{a}_{8}$ ConsGoods + $\mathrm{a}_{9}$ Technology $+\mathrm{a}_{10}$ Healthcare $+\mathrm{a}_{11}$ Oilgas $+\varepsilon$

The above model was used for the initial regression analysis, where CFP was proxied by ROE and ROA, and the size control variable was represented by Assets, Sales and Employees. The extended analysis (over 2004-2009) resulted in the following model:

CFP $=a_{0}+a_{1}$ SRI $+a_{2}$ SIZE $+a_{3}$ RISK $+a_{4}$ ConsServ + $\mathrm{a}_{5}$ Financials $+\mathrm{a}_{6}$ BasicMat $+\mathrm{a}_{7}$ Telecomm $+\mathrm{a}_{8}$ ConsGoods + $\mathrm{a}_{9}$ Technology $+\mathrm{a}_{10}$ Healthcare $+\mathrm{a}_{11}$ Oilgas $+\mathrm{a}_{12} \mathrm{CFP}(\mathrm{T}-1)+$ $\mathrm{a}_{13} \mathrm{CFP}(\mathrm{T}-2)+\mathrm{a}_{14} \mathrm{CFP}(\mathrm{T}-3)+\mathrm{a}_{15} \mathrm{CFP}(\mathrm{T}-4)+\mathrm{a}_{16} \mathrm{CFP}(\mathrm{T}-5)+$ $\varepsilon$

This model once again used ROE and ROA as the financial measures and the same three size variables. The difference however was the stepwise inclusion of the firm's previous CFP. The final analysis looked at CSR from the investors' perspective through the idea of SRI. A Conventional portfolio was created to compare to the portfolio of SRI shares so that any differences could be assessed. Following Viviers, Bosch, Smit \& Bijs (2008) a variety of risk adjusted measures were employed to compare the conventional investments to the socially responsible ones.

$$
\begin{gathered}
\text { Sharpe }_{i}=\left(r_{i}-r_{f}\right) / \sigma_{i} \\
\text { Sortino }_{i}=\left(r_{i}-r_{f}\right) / \delta_{i} \\
\text { Upside Potential Ratio } \\
\text { (UPR }
\end{gathered}
$$

The risk-adjusted measures above are shown in Appendix 1. The use of these measures have the benefit of being market independent and thus useful in light of the composition of the SRI - consisting of the majority of the JSE Top 40. In its totality this paper aimed to examine the social responsibility question from the perspective of the firm as well as the investor - taking into account the long-term as well as shortterm issues.

\section{Data}

The question of SRI in South Africa is a relatively new one, and as a result the amount of research and information into this area is not as extensive as in other countries around the world. One advantage, however, is the fact that the JSE launched the SRI index in 2004 which has been used in this paper as the main proxy for CSR in South Africa. As mentioned previously, the index creation was performed by EIRIS, an independent researcher, and used methods common to earlier academic papers including content analysis, surveys etc. (EIRIS, n.d.). The areas of measurement were aligned with the three pillars of sustainability and included Environment (improve environmental performance, work to reduce and control direct negative environmental impacts; use resources sustainably), Society (commit to social sustainability and good stakeholder relationships; promote development of employees/community; ensure labour standards) and Governance \& Sustainability (uphold good corporate governance practices, work towards long term growth and sustainability). Using SRI participation as the distinguishing feature of responsible companies, a sample of responsible firms was created and compared to a similar sample of conventional firms (those firms of similar size which had never participated in the SRI index). For the short term analysis from the firm perspective, an event study was used where the methodology followed directly from McWilliams \& Siegel (1997). Using the market model based on the JSE All Share Index (J203) abnormal returns around the SRI constituent list announcement dates were calculated and test statistics were derived. From this approach the following hypothesis was tested:

\section{$\mathrm{H}_{1}$ : The market does not price the social factor into a company's shares.}

If there were indeed abnormal returns around the date of announcement then it is plausible that the announcements carried some informational content and that social responsibility has some implicit value for companies. Turning to the investor perspective a portfolio of socially responsible firms was created using the SRI lists as a base. This was then compared to a portfolio of conventional firms by excluding the SRI firms from the JSE and using the next largest companies where size biases were accounted for. Using the Fama and French Three Factor Model, as well as various risk-adjusted measures the SRI companies were compared to conventional firms with the following hypothesis in mind:

\section{$\mathrm{H}_{2}$ : Socially responsible portfolios do not perform better than conventional portfolios}

If it was found that there was a significant difference between the portfolio performances, it could be concluded that SRI firms do indeed perform better than conventional firms. The most important relationship in terms of the firm perspective is that between CSP and CFP. This means that if a link exists between the social responsibility of the firm and its profitability; more thought must be put into the approach business takes to social responsibility. As a result, this would aid in the strategy of the firm as the consequences of decisions can now be fully accounted for; and the hypothesis tested was:

\section{$\mathrm{H}_{3}$ : There is no significant relationship between CFP and CSP}

Any rejection of the above hypothesis would indicate the financial effects of being socially responsible and give an idea as to the benefits or costs of social responsibility to the firm. As mentioned, causality is a key question when it comes to the CFP-CSP relationship. However, due to limitations in CSP proxies as well as research methodologies it is generally difficult to conclusively determine the direction of the relationship. Using a simplified method over a short time period, the relationship 
between CFP and CSP was examined with the possible hypotheses being:

\section{$\mathrm{H}_{4}$ : Good CSP does not result in better CFP}

\section{$\mathrm{H}_{5}$ : Good CFP does not result in greater CSP}

$\mathrm{H}_{6}$ : CSP and CFP do not affect each other mutually and simultaneously in a virtuous circle.

Depending on the results, it could be determined if there is a relationship at all, and in which direction the causal nexus goes. For the short term event study the only data required was the share price of the constituent lists, and therefore the source of data was I-Net Bridge, where the full SRI list of 85 firms (any firm on the JSE which participated in the SRI index at least once) was examined around the announcement dates. In the investor analysis (Three Factor Model; riskadjusted performance measures) the portfolio creation entailed using data from the JSE as compiled in the Wits financial database, referred to as Findata@Wits, where the sample periods looked at were from 1995 until 2009; and from 1999 until 2009. After cross referencing the SRI lists with the Findata@Wits database, there were 53 companies in the 15-year SRI portfolio and 65 in the 10-year SRI portfolio where these two portfolios allowed for the backtesting of the SRI index. The conventional portfolio was created by combining lists of the 74 largest firms by market capitalisation in 1995 and 2009. From the 188 firms in the sample, 74 were included in the SRI index which left 114 firms to be defined as conventional. These were then crossreferenced with the Findata@Wits database and a portfolio of around 79 firms with data was finalized. For the regressions the company lists were used from the procedure described above where the 188 firms over the 1995-2009 period were examined and the relevant accounting data were taken from the McGregor BFA database.

\section{Results}

\section{Short-run event study:}

The short term results as evidenced by the event study indicated that none of the event dates had any influence on the share prices of the SRI constituents. Table 1 shows the test statistics for each announcement date and it can be seen that there were no significant $Z$-scores for any of the events.

Table 1: Event dates and corresponding Z-score statistics for an event study with a 1-day event window

\begin{tabular}{l|l}
\hline Event dates & Z-score \\
\hline 19-May-04 & $-0,011$ \\
\hline 19-May-05 & $-0,029$ \\
\hline 25-Apr-06 & 0,032 \\
\hline 27-Nov-07 & 0,090 \\
\hline 26-Nov-08 & 0,326 \\
\hline 30-Nov-09 & $-0,015$ \\
\hline
\end{tabular}

The results may mean a few different things, however none of them are entirely conclusive. It is possible that the proxy for CSR was not a good enough representation of CSP, or it was not recognized by investors to influence their perceptions about the shares. Another possibility is that the JSE is inefficient and that in spite of the information content of the announcements, the effects were not captured by the event study as they were not instantaneously accounted for in the share prices. For the purposes of this paper market efficiency was taken to hold and thus in the short run there were no relationships between perceptions of CSP and the share price movements (as found in Arlow \& Gannon, 1982; Teoh et al., 1999). An alternative hypothesis is that CSR may only be related with firm profitability over the long term and that if investors can evaluate the potential future impact of positive CSR announcements, they will bid up the price of the firm. The justification behind the use of the event study is that if investors truly valued the social aspect of business, then the announcement of the SRI constituent lists may change investor perceptions about the constituent companies and it is possible that there would be a followthrough effect on share prices. However, the lack of significant statistics (either from CSR not being valued or the proxy not being adequate enough) left the tentative conclusion that there was no relationship in the short term and other avenues needed to be researched.

\section{Portfolio Performance}

For the section examining the relative performance of socially responsible companies, a conventional portfolio was constructed so as to compare it with the portfolio of SRI constituents. The performance model used was Fama and French's Three Factor model, and the portfolio returns were examined using value-weighted as well as equally-weighted portfolios. It was found that the market model could not completely explain the SRI portfolio returns and that there was possibly some other factor driving returns. In contrast, the conventional portfolio had the majority of its returns explained by the model, as expected. The model also showed that for the SMB (Small-Minus-Big) factor measuring size, the SRI portfolio was considered large-cap which was explained by the fact that the majority of the JSE Top 40 firms were SRI constituent companies. Initially the SRI portfolios over the different sample periods were compared against the conventional portfolio for differences in their mean. It was found that the conventional portfolio consistently underperformed the SRI portfolio, while its volatility was lower than the responsible portfolio. Using ttests for the examination of differences in means it was found that the SRI and conventional portfolios were not statistically different and therefore further analysis was required.

Turning to a comparison of risk-adjusted returns, three measures - Sharpe Ratio, Sortino Ratio and Upside Potential Ratio, were taken from Viviers et al. (2008). Using the same portfolios a comparison was conducted and it was found that in all cases (value as well as equally-weighted, for conventional as well as SRI) the shorter 10 year portfolios (SRI99) always outperformed the 15 year portfolios (SRI95). For both the Sharpe and Sortino ratios the SRI 
portfolio over 10 years attained higher risk adjusted returns. An important observation was that the 10 as well as 15 year SRI portfolios both outperformed the conventional portfolio using all three of the measures.

Table 2: Summary of risk-adjusted performance measures

\begin{tabular}{l|c|c|l|c|c|c}
\hline $\begin{array}{l}\text { Risk-adjusted } \\
\text { Measure }\end{array}$ & \multicolumn{2}{|c|}{ SRI (Value) } & \multicolumn{2}{c}{ SRI (Equal) } & \multicolumn{2}{c}{ Conventional } \\
\hline & $\begin{array}{c}\text { SRI } \\
\mathbf{9 5}\end{array}$ & $\begin{array}{c}\text { SRI } \\
\mathbf{9 9}\end{array}$ & SRI95 & $\begin{array}{c}\text { SRI } \\
\mathbf{9 9}\end{array}$ & $\begin{array}{c}\text { Conv } \\
\mathbf{9 5}\end{array}$ & $\begin{array}{c}\text { Conv } \\
\mathbf{9 9}\end{array}$ \\
\hline Sharpe Ratio & 0,175 & 0,444 & $-0,249$ & 0,063 & $-0,745$ & $-0,213$ \\
\hline Sortino Ratio & 0,240 & 0,759 & $-0,370$ & 0,118 & $-1,020$ & $-0,320$ \\
\hline $\begin{array}{l}\text { Upside } \\
\text { Potential Ratio }\end{array}$ & 0,260 & 0,330 & 0,265 & 0,621 & 0,224 & 0,238 \\
\hline
\end{tabular}

Using a simple analysis based on an investment of R1 in both the value-weighted SRI and conventional portfolio indicated that the SRI outperformed attaining a final value of R13,48 versus R10,76. The figure below shows the Value (and Equally) Weighted SRI portfolios along with the conventional portfolio over the sample period.

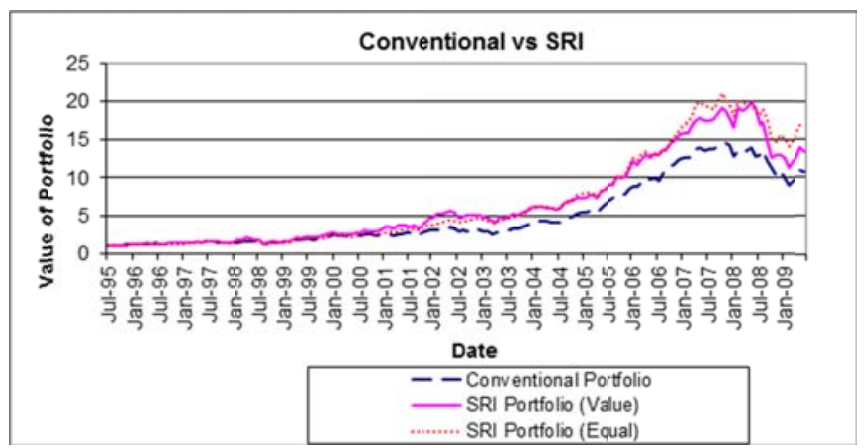

Figure 1: Simple compounding of SRI return series (value- and equally-weighted) versus alternative conventional return series

This graph was produced by compounding the returns series of each of the portfolios, and once again the results seemed to confirm those found by the risk adjusted metrics. An important note to mention is that generally both of these portfolios consistently underperformed the market index, in spite of the fact that the majority of the current Top 40 list comprised a large portion of the SRI portfolio. This may be an artifact of the portfolio creation as they were formed on the basis of SRI and size characteristics only - which may have introduced biases and other risk factors not accounted for. Another explanation is that due to selection issues, although many SRI firms currently comprise the majority of the JSE market capitalization, this may not have been the case in the past. As the market index included all new companies as well as those influenced by booms while the SRI list remained constant over time; this may explain some of the differences in performance.

To provide clarity the market capitalisations of the JSE from 1995 until 2009 were cross referenced to the SRI lists indicated. In the first seven years of the sample the SRI lists did not even have half of the Top 40 companies. As time progressed the SRI portfolio constituents started to represent far more of the Top 40. This may be a result of the portfolio creation process as the portfolios were created using lists from 2004-2009, where the SRI companies were already majority constituents of the Top 40 list. Additional tests, not presented here, examined the robustness of the analysis by restricting the portfolios to the period of the SRI index' existence (2004-2009) as well as restricting the market capitalisations. Generally the results were consistent with those presented above.

\section{Long-term regression analyses}

For the long-term approach regression analysis was the main method followed where, using prior literature as a base (McWilliams \& Siegel, 2000; Callan \& Thomas, 2009; Waddock \& Graves, 1997), the CSP-CFP relationship was examined. The first model used (McWilliams \& Siegel, 2000) tested ROE and ROA against SRI (coded one if the company was in the SRI index at any point in time), a size factor, the long-term debt asset ratio (risk) and industry control variables. The results indicated that in all cases the relationship between ROE and SRI was positive while it was negative between ROA and SRI. As can be seen in Table 3 there was a significant coefficient of 11,18 between ROE and SRI (significant at the 10\% level) when Assets proxied for size, and a significant coefficient of $-1,824$ between ROA and SRI (5\% level) when Sales proxied for size. To this end, there seemed to be some relationship apparent between SRI and CFP; however the different CFP measure seemed to affect the results - bringing to mind the literature's differentiation between long-term and short term measures, where some hypothesized that ROE is related to SRI in the long run.

Table 3: Regression results following McWilliams \& Siegal (2000) using the 1995 - 2009 sample period

\begin{tabular}{|c|c|c|c|c|c|}
\hline 诖 & 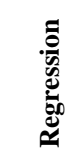 & 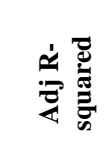 & is & : & 曱 \\
\hline ROE & $1 \mathrm{a}$ & 0,029 & Assets & $10 \%$ & 11,180 \\
\hline ROE & $1 \mathrm{~b}$ & 0,029 & Sales & None & 8,130 \\
\hline ROE & $1 \mathrm{c}$ & 0,017 & Employees & none & 0,048 \\
\hline ROA & $2 \mathrm{a}$ & 0,029 & Assets & None & $-0,616$ \\
\hline ROA & $2 b$ & 0,032 & Sales & $5 \%$ & $-1,824$ \\
\hline ROA & $2 c$ & 0,074 & Employees & None & $-0,002$ \\
\hline
\end{tabular}

As the sample period was over fifteen years, the significant coefficients meant that the results could be potentially important and thus further examination was required. The sample was restricted to the period 2004-2009 when the SRI index was in existence. The difference here was the SRI dummy variable where it was coded one if it was in the index for that specific year. Previous CFP was also included 
as additional variables in a stepwise fashion, and again three measures of size were included.

Table 4: Regression results following McWilliams \& Siegal (2000) using the 2004- 2009 sample period

\begin{tabular}{|c|c|c|c|c|c|}
\hline \multicolumn{3}{|c|}{ ROE } & \multicolumn{3}{|c|}{ ROA } \\
\hline 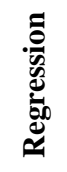 & 司 & 芦 & 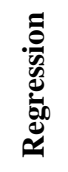 & 承 & 异 \\
\hline 3a1 & 20,82 & $5 \%$ & $4 \mathrm{a} 1$ & 2,05 & none \\
\hline $3 a 2$ & 21,27 & $5 \%$ & $4 a 2$ & 1,08 & none \\
\hline 3a3 & 21,34 & $5 \%$ & $4 a 3$ & 1,87 & none \\
\hline $3 a 4$ & 21,64 & $5 \%$ & $4 a 4$ & 1,91 & none \\
\hline $3 a 5$ & 22,63 & $5 \%$ & $4 a 5$ & 2,21 & none \\
\hline $3 \mathbf{b} 1$ & 21,01 & $5 \%$ & $4 b 1$ & 1,93 & none \\
\hline $3 \mathbf{b} 2$ & 21,13 & $5 \%$ & $4 b 2$ & 0,89 & none \\
\hline $3 \mathbf{b 3}$ & 21,20 & $5 \%$ & $4 b 3$ & 1,74 & none \\
\hline $3 b 4$ & 21,51 & $5 \%$ & $4 \mathrm{~b} 4$ & 1,79 & none \\
\hline 3b5 & 22,53 & $5 \%$ & 4b5 & 2,11 & none \\
\hline $3 c 1$ & 23,17 & $5 \%$ & $4 c 1$ & 1,80 & none \\
\hline $3 c 2$ & 17,17 & $10 \%$ & $4 c 2$ & 1,08 & none \\
\hline $3 c 3$ & 18,34 & $10 \%$ & $4 c 3$ & 1,49 & none \\
\hline $3 c 4$ & 21,33 & $10 \%$ & $4 c 4$ & 1,84 & none \\
\hline $3 c 5$ & 25,14 & $5 \%$ & $4 c 5$ & 2,07 & none \\
\hline
\end{tabular}

This resulted in fifteen regressions for each ROE and ROA. The most interesting observation from this model was that the SRI coefficients were positive in all thirty of the regressions; and in the ROA models every coefficient was insignificant at all traditional levels, contrasting with the ROE models which showed significance for all fifteen SRI coefficients. These results were robust to the size proxy as well as the degree of prior CFP included in the model. The only caveat here being that the sample size was limited to six years, thus future investigation may be needed to confirm these results. The coefficients for the ROE models varied in magnitude from 17,17 to 25,14 and these suggest a significant advantage for the socially responsible firms. Using a Generalised Method of Moments two-step system with Windmeijer corrections as a test for robustness; significance for five of the six models disappeared - as shown in Table 5. It was found that for the ROE model using employees as the size proxy there was still an economically and statistically significant SRI coefficient; therefore after accounting for possible biases there still was some evidence of a potential relationship between CSP and CFP.
Table 5: Regression results following McWilliams \& Siegal (2000) using a generalized method of moments two-step system with Windmeijer Corrections

\begin{tabular}{|c|c|c|c|c|c|}
\hline \multicolumn{3}{|c|}{ ROA } & \multicolumn{3}{|c|}{ ROE } \\
\hline 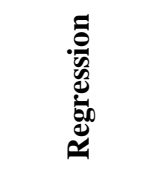 & 佘总 & 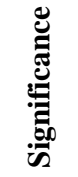 & 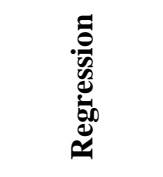 & 承 & 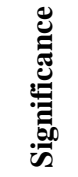 \\
\hline Assets & $-1,25$ & none & Assets & 14,51 & none \\
\hline Turnover & $-1,43$ & none & Turnover & 21,67 & none \\
\hline Employees & 0,15 & none & Employees & 23,34 & $5 \%$ \\
\hline
\end{tabular}

The next set of models included the three size proxies simultaneously as well as including them in quadratic form as a test for linearity, based on the Callan and Thomas (2009) model. Shown in Table 6, it was apparent that while size was important and could not be omitted from the models, the CSP coefficients were not statistically significant in any of the specifications. Thus, using this model there seemed to be no significant relationship between CSP and CFP. An interesting observation was that both of the SRI coefficients in the ROA model were negative, while the ROE coefficients were positive - a finding similar to that using the 15 year model previously noted. Once again although the trend between ROE, ROA and SRI seemed to confirm earlier results, there were no clear cut conclusions to be made from these models.

Table 6: Regression results for Callan \& Thomas (2009) - fully specified model including quadratic form

\begin{tabular}{|c|c|c|c|c|c|}
\hline \multicolumn{3}{|c|}{ Linear } & \multicolumn{3}{|c|}{ Quadratic } \\
\hline 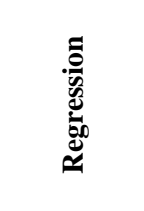 & 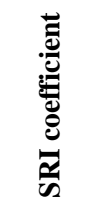 &  & 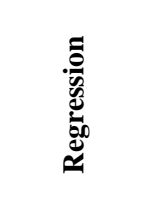 & 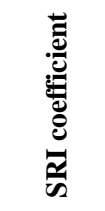 & 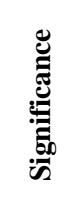 \\
\hline $\begin{array}{c}5 a \\
\text { Operating } \\
\text { Profit } \\
\end{array}$ & 13916 & none & $\begin{array}{c}5 b \\
\text { Operating } \\
\text { Profit } \\
\end{array}$ & -68461 & none \\
\hline 6a ROA & $-0,63$ & none & 6b ROA & $-0,32$ & none \\
\hline 7a ROE & 3,58 & none & 7b ROE & 2,90 & none \\
\hline
\end{tabular}

The final model based on Waddock \& Graves (1997) examined causality by hypothesizing about the direction of the relationship. As SRI was a binary variable, logistic regressions were combined with linear regressions to test the directionality in the relationships, where the results have been presented in Table 7 and Table 8. For these models ROE and ROA were tested to see if they predicted SRI participation, and then SRI was looked at to see if it could predict the CFP. Once again there seemed to be no significance for the SRI coefficients, although the signs were similar to those previously reported. Overall the regression analyses offer varying results, thus the theoretical 
basis justifying the use of models is useful in understanding the results.

Table 7: Linear regression following Waddock \& Graves (1997) - using social performance as a predictor of financial performance

\begin{tabular}{|c|c|c|c|c|c|}
\hline \multicolumn{3}{|c|}{ ROE(t+1) } & \multicolumn{3}{|c|}{$\operatorname{ROA}(t+1)$} \\
\hline 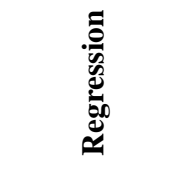 & 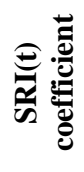 & 苛 & 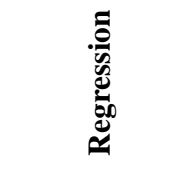 & 荬 & 苞 \\
\hline 8a Assets & 6,12 & none & 8d Assets & $-0,12$ & none \\
\hline 8b Turnover & 4,36 & none & 8e Turnover & $-1,35$ & none \\
\hline $\begin{array}{c}\text { 8c } \\
\text { Employees }\end{array}$ & 3,62 & none & 8f Employees & 0,24 & none \\
\hline
\end{tabular}

Table 8: Logistic regression following Waddock \& Graves (1997) - using financial performance as a predictor of social performance

\begin{tabular}{|c|c|c|c|c|c|}
\hline \multicolumn{3}{|c|}{ SRI(t) } & \multicolumn{3}{|c|}{ SRI(t) } \\
\hline 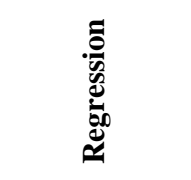 & 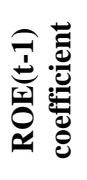 & 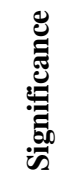 & 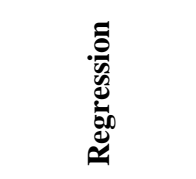 & 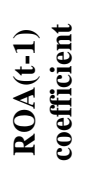 & : \\
\hline 9a Assets & 0,00 & none & 9d Assets & 0,00 & none \\
\hline 9b Turnover & 0,00 & none & 9e Turnover & $-0,00$ & none \\
\hline $\begin{array}{c}\text { 9c } \\
\text { Employees }\end{array}$ & 0,00 & none & 9f Employees & 0,02 & none \\
\hline
\end{tabular}

Tying CSR frameworks together (Fitch, 1976; Carroll, 1979; Porter \& Kramer, 2006) it is possible to understand why CSP can be related to CFP. Orlitzky et al. (2003) found a positive association between CSP and CFP across industries as well as study contexts. Due to the nature of the CSP proxy, there could be no differentiation between optimal levels of CSP and therefore the only analysis available using these measures was to examine the relationship between firms classified as socially responsible and those classified as conventional. The evidence has shown instances where there appears to be no relationship (which in itself can be taken as a positive due to the positive externalities of social responsibility); however the fully specified extension of McWilliams \& Siegel (2000) gave the clearest evidence of a relationship between ROE and SRI. This finding should not be taken lightly and hopefully future research will be able to confirm and support its existence.

\section{Summary and conclusions}

It was found in this paper that there was no simple conclusion to be drawn when all the evidence was examined in its entirety. From the short term analysis, it was evident that there were no significant statistics, thus the announcement dates had no significant effects on the SRI companies' share prices; and therefore $\mathrm{H}_{1}$ could not be rejected. It is tempting to take this result at face value; however it is possible that a key assumption has been violated in terms of market efficiency. In addition the, limitations faced by this study, most importantly the nature of the CSP proxy, means that while the findings may be informative they are by no means conclusive and there is still a lot of work to be done. As stated the most stringent restriction was that of the proxy where the dichotomy of the variable as well as its limited existence should be taken into account.

From the investors' perspective, using raw returns it seemed that the SRI portfolio outperformed the conventional portfolio. Using the risk-adjusted measures it was found that in both time periods the SRI portfolio outperformed the conventional portfolio, using all three of the performance measures. From the evidence it seems plausible that $\mathrm{H}_{2}$ can be rejected, and that the socially responsible portfolio performed better than the conventional one. Once again, the limitations in portfolio creation should be noted and further research should be done to support these findings. Looking at the long-term relationships the varying regression models gave instances where CSP was a significant predictor of CFP - where SRI firms appeared to be more profitable. The tests of causality, however, found no significant relationship in either direction. The evidence from the expanded McWilliams \& Siegel (2000) models showed highly significant relationships between ROE and the SRI coefficient (fifteen out of fifteen significant coefficients versus zero for the ROA specifications). The outperformance ranged from $17,17 \%$ to $25,14 \%$ in ROE where these numbers are not trivial and suggest there may be some valid reasoning behind the CSR movement. This in addition to the other findings of the regression analysis lead to $\mathrm{H}_{3}$ being rejected - suggesting that there is a relationship; however the direction could not be established. The final regression analysis looked at causality, and there seemed to be no relationship of either CFP or CSP affecting each other. Following from this, hypotheses $\mathrm{H}_{4}$ and $\mathrm{H}_{5}$ could not be rejected. In addition the hypothesis $\mathrm{H}_{6}$ relating to the virtuous circle where CFP and CSP affect each other mutually and simultaneously could not be rejected.

Joseph Stiglitz has stated that SRI anticipates broader social movements and in this way is thinking ahead (as cited in Petrillo, 2009). By taking note of this topic investors may have a better handle on future movements from companies and markets. Understanding that SRI anticipates future social changes is key to driving the social investment movement forwards and by accepting the fact that socially responsible firms are not wasting resources meant for shareholders, investors can recognize the legitimacy of corporate CSR initiatives. Orlitzky et al. (2003) noted that CSP needs to be used as a reputational lever, and the key to reaping benefits from CSP is a return from reputation. In addition, it has been noted that to benefit from CSR, the upside of these projects need to be promoted; thus by talking up the positive aspects investors and investment professionals alike can join the social investment movement. As more stakeholders start to see the benefits and 
participate, more benefits shall come through and in this way firms as well as society will be able to reap the rewards.

Although many reasons have been suggested for CSR to be pursued, Porter \& Kramer (2006) suggest that many of the arguments are very limited and too general in nature. While sustainability is a noble goal, attempting to coerce everyone to be sustainable according to the same standards does not work, and it may be better for firms to be as sustainable as their circumstances allow. By taking their business objectives and strategies into account, companies should be socially responsible while maintaining value for themselves as well as their surrounding communities. In this way, tradeoffs are considered when looking at CSR decisions and shareholder interests are not sacrificed for vague social commitments that companies are expected to appease. It has been suggested that there will never be a final word on the subject of CSR as at its core, its nature is to respond to the changing political and social landscape - as is the case with companies. Although this paper has attempted to answer some of the initial questions posed, it is important to note that the findings should matter not only to practitioners of socially responsible investing, but also to all investors, and it is in this light that the findings of this paper are considered.

Bernstein (2010) has suggested that being socially responsible as defined by developed economies may hurt economic growth in the long-run, and actually result in poverty for a longer period of time. While recognizing the responsibility business has in society is important, its economic role as a developer of economies needs to be incorporated into the social responsibility model. The idea of economic responsibility has been suggested and this coupled with the other ethical and social responsibilities facing the firm may assist stakeholders to take CSR more seriously as it promotes adherence to social responsibilities without neglecting shareholders. In this way companies can perform in the non-traditional spheres of business while being mindful of the limitations inherent in their relationships with the shareholders of the firm. This restriction relates to the idea that not all socially responsible behaviours are appropriate for economies at different stages of development, thus the ultimate goal of the firm may be thought of as being "responsible" - responsibly.

As more research is performed, it may be that a new look at CSR is required where public goods may be effectively outsourced to private enterprise. CSR can be seen as a strategic opportunity where government assistance through tax and other incentives may result in firms using their expertise to provide public goods with much higher levels of efficiency. In terms of the research, the examination of firms having different strategic postures, and other longitudinal studies may all further this subject. In addition there is a need for an improved strategic framework as well as methodological improvements. Additional important avenues for future work include finding more appropriate measures of CSP, and following from this, analysis into the causality underlying the relationship between CSP and CFP; as well as any differences between varying levels of social performance. Areas pertinent to the South African context but not covered in this paper include Black Economic Empowerment, the impact of AIDS and other socioeconomic issues such as land reform and education. These are key issues in the future growth of South Africa and finding a resolution where business and society can both benefit is paramount to unlocking the potential of South Africa.

\section{References}

Anderson, S. \& Cavanagh, J. 2000. 'Top 200: The rise of global corporate power'. Report compiled for the Institute of Policy Studies, Washington.

Arlow, P. \& Gannon, M.J. 1982. 'Social responsiveness, corporate structure, and economic performance', The Academy of Management Review, 7(2): 235-241.

Aupperle, K.E., Carroll, A.B. \& Hatfield, J.D. 1985. 'An empirical examination of the relationship between corporate social responsibility and profitability', The Academy of Management Journal, 28(2): 446-463.

Bernstein, A. 2010. The case for business in developing economies. Penguin Books South Africa.

Callan, S.J. \& Thomas, J.M. 2009. 'Corporate financial performance and corporate social performance: An update and reinvestigation', Corporate Social Responsibility and Environmental Management, 16(2): 61-78.

Carroll, A.B. 1979. 'A three-dimensional conceptual model of corporate social responsibility', The Academy of Management Review, 4: 497-505.

Cochran, P.L. \& Wood, R.A. 1984. 'Corporate social responsibility and financial performance', The Academy of Management Journal, 27(1): 42-56.

Diltz, J.D. 1995. 'The private cost of socially responsible investing', Applied Financial Economics, 5: 69-77.

EIRIS. n.d. 'Key facts \& statistics' [online] URL:http://www.eiris.org/news/statistics.html. Accessed 21 September 2009.

Fitch, H.G. 1976. 'Achieving corporate social responsibility', The Academy of Management Review, 1(1): 38-46.

Friedman, M. 1970. 'The social responsibility of business is to increase its profits', The New York Times Magazine, 13 Sep 1970: 32-33.

Gompers, P.A., Ishii, J.L. \& Metrick, A. 2003. 'Corporate governance and equity prices', Quarterly Journal of Economics, 118(1): 107-155.

Government Employees Pension Fund. 2009. 'Responsible investment explanatory memorandum'. Government 
Employees Pension Fund. [online] URL: http://www.gepf.gov.za/Investments/Pages/default.aspx. Accessed 21 September 2010.

Grossman, B.R. \& Sharpe, W.F. 1986. 'Financial implications of South African divestment', Financial Analysts Journal, 42(4): 15-29.

Kinder, P. \& Domini, A. 1997. 'Social screening: Paradigms old and new', Journal of Investing, 6(4): 12-19.

Masie, D. 2008. 'Socially responsible investing: Naughty but nice.' Financial Mail 8 Aug 2008.[online]URL: http://secure.financialmail.co.za/08/0808/moneyinvest/hmon ey.htm. Accessed 6 September 2010.

McGuire, J.B., Sundgren, A. \& Schneeweis, T. 1988. 'Corporate social responsibility and firm financial performance', The Academy of Management Journal, 31(4): 854-872.

McWilliams, A. \& Siegel, D. 1997. 'Event studies in management research: Theoretical and empirical issues', The Academy of Management Journal, 40(3): 626-657.

McWilliams, A. \& Siegel, D. 2000. 'Corporate social responsibility and financial performance: Correlation or misspecification?' Strategic Management Journal, 21(5): 603-609.

Moskowitz, M.R. 1972. 'Choosing socially responsible stocks’, Business and Society Review, 1: 71-75.

Norman, W. \& MacDonald, C. 2003. 'Getting to the bottom of "Triple Bottom Line", Business Ethics Quarterly, 14: 243-262.

Orlitzky, M., Schmidt, F.L. \& Rynes, S.L. 2003. 'Corporate social and financial performance: A meta-analysis', Organization Studies, 24(3): 403-441.

Petrillo, A. 2009. “"SRI is thinking ahead": Nobel winner Joseph Stiglitz on investing, regulation, and corporate governance'. [online]

URL:http://blog.riskmetrics.com/esg/2009/02/theft-is-noteconomic-growth-nobel-winner-joseph-stiglitz-on-sriregulation-and-corporate-governance.html. Accessed 23 March 2010.

Porter, M.E. \& Kramer, M.R. 2006. 'Strategy \& society: The link between competitive advantage and corporate social responsibility', Harvard Business Review, 84(12): 78-92.

Social Investment Forum. 2012. 'Report on sustainable and responsible investing trends in the United States 2012. Executive Summary'. [online] URL: http://ussif.org/resources/pubs/documents/USSIFTrends201 2ES.pdf. Accessed Dec 2012.
SRI Index. 2009a. 'Corporate and investor support grows for JSE's SRI index'. [online] URL:http://www.jse.co.za/Libraries/SRI_Annual_Review_Process_-2009_Review_Results/ press_rēease_2009.sflb.ashx. Accessed 18 April 2010.

SRI Index. 2009b. 'Background and selection criteria'. [online] URL: http://www.jse.co.za/AboutUs/SRI/Criteria.aspx. Accessed_22 September 2010.

Statman, M. 2000. 'Socially responsible mutual funds. As corrected October 2000', Financial Analysts Journal, 56(4): 71-77.

Teoh, S.H., Welch, I. \& Wazzan, C.P. 1999. 'The effect of socially activist investment policies on the financial markets: Evidence from the South African boycott', The Journal of Business, 72(1): 35-89.

United Nations. n.d. 'The principles for responsible investment' [online] URL:http://www.unpri.org/principles/. Accessed 1 Nov 2009.

Viviers, S., Bosch, J.K., Smit, E. \& Buijs, A. 2008. 'The risk-adjusted performance of responsible investment funds in South Africa', Investment Analysts Journal, 2008, 68: 3956.

Waddock, S.A. \& Graves, S.B. 1994. 'Institutional owners and corporate social performance', The Academy of Management Journal, 37(4): 1034-1046.

Waddock, S.A. \& Graves, S.B. 1997. 'The corporate social performance - financial performance link', Strategic Management Journal, 18(4): 303-319. 


\section{Appendix 1 Portfolio Analysis}

\section{Sharpe Ratio:}

where:

$$
\text { Sharpe }_{i}=\left(r_{i}-r_{f}\right) / \sigma_{i}
$$

$r_{i}=$ The mean annualised rate of return of fund i during a specified time period

$r_{f}=$ The mean annualised rate of return of a risk free asset during the same time period

$\sigma_{i}=$ The annualised standard deviation of the rate of return of fund $i$ during the pecified time period

\section{Sortino Ratio:}

where:

$$
\text { Sortino }_{i}=\left(r_{i}-r_{f}\right) / \delta_{i}
$$

$r_{i}=$ The average annualised rate of return for fund $\mathrm{i}$ during a specified time period

$r_{f}=$ The average annualised rate of return on a risk free asset during the same time period

$\delta_{\mathrm{i}}=$ The annualised downside deviation of the rate of return of fund $i$ during the specified time period and:

where:

$$
\delta_{i}=\sqrt{\int_{-\infty}^{\tau}\left(\tau-r_{i}\right)^{2} f\left(r_{i}\right) d r_{i}}
$$

$\tau=$ the investor's threshold or MAR value

$r_{i}=$ the return of fund $i$ with a cumulative probability density function $\mathrm{f}($.

\section{Upside Potential Ratio:}

where:

$$
\mathrm{UPR}_{\mathrm{i}}=\theta_{\mathrm{i}} / \delta_{\mathrm{i}}
$$

$\theta_{\mathrm{i}}=$ Fund's i's upside-potential

$\delta_{\mathrm{i}}=$ Fund i's downside deviation and:

where:

$$
\theta=\int_{\tau}^{\infty}\left(r_{i}-\tau\right) f\left(r_{i}\right) d r_{i}
$$

$\tau=$ The investor's threshold or MAR value

$r_{i}=$ The return of fund $i$ with a cumulative probability density function $\mathrm{f}($. 